\title{
Dimensions for the Expression of European Identity
}

\author{
Robert Miller, Markieta Domecka, Dirk Schubotz and Maruška \\ Svašek
}

The chapters that make up this edited book all arise from a single European Commission Framework 7 collaborative research project, EUROIDENTITIES: 'The Evolution of European Identity: Using biographical methods to study the development of European identity', that ran from early 2008 through 2011. The seven partner teams that made up the project were chosen to represent as widely as possible the experience of recent European history and different parameters of interacting with 'Europe'. The nations in Euroidentities included representatives of the original states of the European Union, both its centre (Germany) and its western (Northern Ireland and Wales) and southern (Italy) peripheries. The new Accession States of the European Union were represented by a large central state (Poland) and two smaller peripheral states (Estonia, denoting a relatively economically successful new member state, and Bulgaria, one less so).

The Euroidentities project had its origins in the perception that the bulk of previous empirical work on European identity had been driven by an elitist, 'top down', political science perspective that mirrored the approach of Eurocentric institutions, most notably the European Union itself, towards encouraging or, depending upon one's point of view, imposing Europeanisation upon reluctant populations. The period during which the project was being developed coincided with the rejection of the European Constitution by referenda in the Netherlands and France and the Lisbon Treaty that effectively replaced it was making its uncertain way towards ratification at a time that roughly coincided with the beginning of the project.

As part of its core strategy, the Euroidentities project employed a minimally structured mode of data collection - in-depth biographical narrative interviews in order to give its interviewees the maximum possible range to express their lives from their own perspective - that is, to promote the agency of the research subject. Its core method of analysis, described in depth in the following chapter, 'Method in Practice: Autobiographical 
narrative interviews in search of European phenomena', centres on the biographical narrative approach. Some features that set Euroidentities apart from traditional academic biographical research are its scale - by the end of fieldwork well over 200 lengthy life story interviews had been collected by the project teams - and a strong policy bent at its core. ${ }^{1}$ While findings from Euroidentities are appearing elsewhere ${ }^{2}$ the current edited volume can be considered the definitive account of the project since it contains an extensive methodological chapter and chapters written by all the partner teams and substantive topic-based 'work packages' that made up the project that are intended to present the most significant analysis findings to date.

\section{The biographical narrative method as a strategy}

Crucially for Euroidentities, core features of the biographical narrative method allow a 'bottom up', approach to assessing the extent to which a European identity or identities are evolving in Europe.

First, biographical narrative interviews are designed to allow the interviewee maximum leeway in expressing their own life history from their own perspective. As is explained in depth in the following chapter, this was effected in the Euroidentities project by a non-directive approach to conducting interviews in which all interviews began with a single 'eliciting question' in which the interviewee was asked to tell the story of their life in whatever manner they wished, emphasising or speaking about the parts of their life that they desired to cover in whatever chronological or non-chronological order they cared to follow. Typically, this led to a lengthy extempore narration. Only after the narrative was complete did the interviewer move carefully in steps to a more interrogative mode of questioning. This mode of interviewing was designed to elicit and maintain the gestalt, or spirit, of the interview for as long as possible giving the interviewee maximum agency and 'voice'.

Second, the subject of the interviews - the interviewees' own lives - lends itself to the core topic of the Euroidentities project - the evolution of a European identity or identities across time. Arguably, a biographical

\footnotetext{
${ }^{1}$ Euroidentities employed a variety of methods to effect significant policy impact. These included: holding both the Interim and Final Conferences in Brussels in order to include policymakers, their advisors, lobbyists and representatives from civil society organisations with a European interest in the project's deliberations; generating a number of 'lay-friendly essays' and policy briefings (Davis et al., 2011; Draganova et al., 2011; Schütze, 2011b; Spanò et al., 2011a); and, inspired by Abbott's (2007) 'lyrical Sociology', a 'virtual' depiction of the project's results that is a collection of audio quotes paired with visual photographic images.

${ }^{2}$ Most notably a special edition of the journal Przeglad Socjologiczny, 60(1), that is devoted solely to articles stemming from the project.
} 
interview has the capacity to reveal, albeit imperfectly, the psychological processes and transformations that a person has gone through during their life to arrive at their current sense of self and identity. Being given licence to tell someone, usually a total stranger, the story of your life in any way that you wish without any constraints on the time this may take or on the length that you can dwell on any given facet of your life, with all this taking place in a context in which you have been led to believe that no judgement will be made about what you choose to reveal, is a unique experience that does not have a parallel in everyday life. In at least some cases, the interviewee may journey back to a previous view they held of the world and, rather than the standard constructionist standpoint that the reality of the interview is one being built up in a hermeneutic interaction between researcher and subject, the interviewee may in fact (re)experience a previous psychological state of consciousness and commu- nicate this to the interviewer. While this latter point is debatable, there is no doubt that the Euroidentities project did succeed in eliciting many lengthy and reflective accounts of lives.

Third, the grounded theory nature of biographical narrative analysis promotes person-centred, 'bottom-up' results. While there were differences across the teams in their approaches to analysing the interviews, ${ }^{3}$ each did follow a common grounded theory mode of analysis. Hence, rather than testing some pre-existing models of Europeanisation, the results of the project genuinely have grown out of the interviews. So, in contrast to the all- too-common alternative (one's privileged method being imposed willy-nilly upon a research topic), the method and methodological approach employed by Euroidentities was one strategically chosen as the best possible practical means of studying the potential evolution of a European identity or identities within the constraints of a research project with a limited time span. This 'fit' between research problem and method has been the vital core impetus that has informed and driven the project through to its current publication phase, some of the results of which you will see in the chapters that follow.

\section{'Sensitised groups'}

At the same time, we were aware from pretest interviews that took place before the project began that simply asking a random sample of people to relate their life stories would elicit very little, if any, spontaneous material of relevance to the study of a possible developing sense or senses of being a European. This led to the decision to target a number of 'sensitised groups' - aggregates of persons whose life experiences could be anticipated to have caused them to reflect upon their situation of living within the continent of

\footnotetext{
${ }^{3}$ Discussed in depth in the following methodological chapter.
} 
Europe and perhaps to be challenged or changed by these experiences. After some considerable debate, the project chose five 'sensitised groups':

- The Educationally mobile - People who have had significant experience of study abroad (e.g. as Erasmus exchange students), but, crucially, interviewed later in their lives. Has the cross-national educational experience when they were young had a permanent effect or was it just a transitory encounter with another society? Investigating the biographical significance for later phases in one's life of educational experience in another country allowed an assessment of the extent to which sponsored educational mobility is realising its greater goals of promoting a permanent change in perspective and a lasting integration across European national borders.

- Transnational workers - People who make up this large aggregate category have worked or are working abroad for a significant portion of their lives. Here, both instrumental considerations such as coping with different regulatory systems, border controls as well as the encounter with a different culture (often including the imperative to learn a new language) could be relevant. Both 'high end' technologically qualified workers or professionals and 'low end' menial workers were interviewed.

Transnational workers were those whose labour market activity had resulted in a significant amount of cross-European experience. A key discriminator for inclusion in this group was 'significant'. A casual labourer or student who worked for a short period of time in another country and then returned home did not fall into this category. However, an economic migrant who has spent a significant portion of their life working abroad in another part of Europe, a businessperson for whom cross-border contacts and markets are essential, or a person whose move for work-related reasons has led to their making links in the host country beyond those that are solely job-related (such as bringing their spouse and children to live with them, becoming involved in the life of the local community or even forming a partnership with someone in the host country) could be included.

- Farmers - Farming takes place within a structure of European-wide regulations, subsidies and markets that could be expected to cause farmers, even though they remain located in one place, to think about themselves in a European context. Farmers from the 'old' Member States in particular have a long tradition of dealing with European legislation and regulations, with the economic movements of the European agrarian market and with lobbying for their political concerns and advantages in Brussels through their associations and political parties which are specifically concerned with their economic welfare. In addition, they increasingly must take European environmental requirements into account. At the same time, 
farmers could be defined as a more static group who are strongly affiliated with the nation and the national due to their bonds to the land.

A further rationale for including farmers was based on their heterogeneity as a social group (in terms of social structure, values and identities), with the starting point being that the construction of biographies of farmers from the 'old' and the 'new' Member States could be anticipated to have different grounds and diverse development modes.

- Cultural contacts - Originally this aggregate was to have focussed upon particular types of transnational workers - those engaged in cultural work and contacts, both in terms of 'High' Culture (e.g. classical musicians) and 'low'/ popular culture (e.g. Eurovision or tourism and other leisure travel, soccer and other cross-national sports supporters and participants) that span Europe, with the rationale that these types of activities, often spontaneous, may exert more influence towards the development of European-wide perspectives by members of the general public than consciously imposed 'top down' attempts to promote a European consciousness. In the end, this work package concentrated on crosscultural educational contacts.

- Civil society organisations - Civil society organisations (CSOs) (defined by the project as not-for-profit, non-commercial and in pursuit of a common purpose for the public interest) are an important feature of public life within Europe. The activities of these CSOs may span countries and have a specific European or cross-border context. The project concentrated on workers within two types of civil society organisations: environmental groups, since a core tenet of the 'green movement' is that environmental problems transcend borders; and cross-border peace and reconciliation groups.

In effect, the decision to target sensitised groups and the actual categories chosen were calculated risks. We could not know for sure that we would elicit relevant material until the first interviews began to take place. Fortunately, it is a gamble that paid off. While few of the interviewees' life stories have 'European identity' as a core theme, Europe as a social field of endeavour and orientations to Europe and European institutions, cultures and issues feature prominently both explicitly and implicitly in the interviews. ${ }^{4}$

\footnotetext{
${ }^{4}$ Admittedly, the ethical requirements of needing to explain to a potential interviewee the background of the project, why they have been chosen to be approached for an interview and the uses to which their interview material might be put and so on, to say nothing of the actual name of the project - Euroidentities - meant that interviewees were well aware of the topic of the research. Many interviewees clearly did attempt to tailor the relation of their life story towards what they knew was the project's focus. It also must be admitted that the nature of several of the sensitised groups - persons possessing educational qualifications, those in 'high end' occupations, activists in cross-border civil society organisations - did have the effect of building an upper middle class bias into our sampling strategy.
} 
Preliminary analyses of the interviews led us to decide to generate two additional 'sensitised group' categories from within the body of interview transcripts that had been collected:

- External to Europe - During the first main analysis workshop of the project as a whole, we realised that we were in danger of falling into the trap of seeing 'Europe' in a stereotypical way; to put it bluntly, as 'white' and 'Christian'. By bringing together interviews scattered across the original 'sensitised group' categories and also carrying out some additional inter- views, we created a new category of persons who had either originated from outside Europe ${ }^{5}$ or been born in Europe but had spent a significant portion of their lives living outside the continent. The former aggregate eventually proved very fruitful for the broad research goals of the project as they reported an experience of having one's identity as a European challenged both officially through issues such as citizenship status and visas and unofficially through 'othering' reactions from the 'native' population ranging from mild scepticism about a person who did not fit into someone else's stereotype of what a 'European' 'should be' through to xenophobic prejudice and racism.

- Intimate relations - Another feature that emerged strongly from the first analyses was the significance of cross-border primary relationships; either being the child of parents from two different countries and/or, even more significantly, having experience of a close personal relationship with a person from another country. In either case, people had close exposure to at least one other national culture that, because the exposure comes about as a consequence of one's closest personal involvements, almost inevitably must affect one's core sense of self. If spouses or parents come from different countries, contradictions between cultural backgrounds and the need to resolve them can be more intense and urgent than in other types of social relationships. The emotional intensity that is part and parcel of everyday family life makes mixed families a qualitatively different group that is worthy of being treated separately.

The original five sensitised groups formed the empirical core of Euroidentities, with each of the groups forming one of the substantive work packages ${ }^{6}$ of the project. Along with the two latter additional sensitised groups, these became the foci of the project's analysis and form the basic structure of this book. All teams interviewed respondents who fell into the

\footnotetext{
${ }^{5}$ Either through migrating to Europe from outside the continent or being the children of intercontinental migrants.

${ }^{6}$ European Commission Framework projects are organised into 'work packages', delimited areas of work within the overall project with distinct goals. Often, as in the case of Euroidentities' five sensitised groups, they are determined by a certain topic or area of substantive interest.
} 
'educationally mobile' and 'transnational worker' sensitised groups and subsets of teams interviewed respondents representing the other groups. A strong empirical finding from the outset was that, aside from the farm- ers, there was a considerable overlap between groups. For instance, patterns such as an educationally mobile person who had married someone they met during their exchange who was now living and working in another European country with their partner or a cross-border worker with a civil society organisation who originally had become interested in the values expressed by the organisation due to an early youth exchange experience were not uncommon. This gave the project scope for expanding the number of sensitised groups after fieldwork was underway and meant that the actual numbers of cases available for analysis under any given group heading were larger than the number of cases that were interviewed for that group.

\section{Dimensions of European identity}

While the analysis approaches employed by Euroidentities were strongly influenced by grounded theory precepts, we were acutely aware from the outset that we needed to develop a priori views about the types of experiences, opinions, attitudes and so on that might be conveyed in the biographical interviews which could be considered relevant to a person's sense of identification with Europe or with being a European, if only so that during analysis we would be able to realise when our interviewees were alluding to these issues. This led us, beginning with an early planning workshop held in Belfast two and a half years before the project actually commenced, to discuss the different types of phenomena that could be related in a person's life story that could have a biographical impact that might affect their sense of self-identification as a European or the relation between themselves and Europe. This discussion, originally a 'thought exercise' during the time the application was being developed, continued in a progressively more grounded manner throughout the fieldwork phase and well into analysis.? Originally, what are now called 'dimensions' were termed 'levels' since we had the idea that some types of phenomena or influences were nested within or stemmed from larger categories. When looked at more carefully, particularly in the light of actual findings, this supposition proved to be largely untenable and the label 'levels' was changed to 'dimensions' in order to avoid conveying the implication that some types of phenomena were more fundamental or should be prioritised above others. The categories that are now 'dimensions' have

\footnotetext{
${ }^{7}$ For an interesting snapshot of the project's thinking about these dimensions at the time that the original application was submitted to the European Commission, see Miller and Schütze (2011).
} 
also undergone a progressive refining in which conceptual overlaps have been clarified and separated out. The end result to date is that there are now eight distinct dimensions for the expression of European identity ${ }^{8}$ that will be discussed in turn further:

- Multiple social identities and biographical identity

- Transnational intimate relationships

- Collective action

- Cultural production and intercultural translation

- Inclusion/Exclusion

- Standardisation and regulation

- Structural conditions and opportunity structures

- The public sphere and state-regulated institutions

Before commencing, it is important to recognise that these dimensions are intended to be conceptually distinct phenomena. Several dimensions are likely to appear in any given interview, perhaps even in the same sentences. Also, the following deliberately has not been numbered in to avoid conveying any sense of hierarchy, ordering or progression in the dimensions. A different sequence could be just as valid. In each case, the dimension will be presented along with some discussion of the mechanisms by which it might be expressed and, by way of introduction to the following chapters, sensitised groups where the dimension has been particularly prominent.

\section{Multiple social identities and biographical identity}

Geographically defined identities can be expressed at many levels - the local, regional, national and international as well as the European. The stories often included multiple frames of reference, a clear sign of transnational experience. The interviews demonstrated that identities are multiple, changing, and at times conflicting. In their self-narratives, interviewees moved in and out of narrative episodes in which they remembered, constructed and sometimes visibly relived past experiences, and frequently consciously reflected on past, present and future selves and touched upon ambiguities. While in some interviews individuals identified with Europe at least somewhere in the course of their self-narration, in many others, interviewees did not mention Europe as a frame of reference, and rather identified with other entities, including countries, towns, families, friends, partners, professional groups (academics, farmers) or civil society organisations. Only rarely was this connected directly to ideas about 'Europe'; although in some cases, 'Europe' and 'European identity' were presented as a form of conflict prevention (Nazi Germany, the Northern

${ }^{8}$ Or its opposite, a lack of self-identification as a European, or its converse, a sense of identity, but not with Europe. 
Ireland conflict) and as tools to undermine national labelling or, in the case of some of our 'External to Europe' group, who had come to Europe from areas where individual human rights are more under threat, as a beacon of the rule of law.

In many interviews narrators spoke of multiple attachments to people and places in different localities, using local, translocal, national and transnational frames of reference. Rather than layered or nested identities, it is more sensible to speak of a mosaic of situationally relevant identities with the context determining whether locality, region or nation is relevant. Especially in the biographical narratives of transnational workers, people involved in transnational intimate relationships, and children from mixed marriages, feelings of diasporic and transnational belonging were expressed frequently. Transnational workers often spoke of multiple attachments to family members and friends in the homeland and their current place of residence. They also spoke of connections to and affections for particular places, cultural traditions, food, life styles, and so on. Their multiple attachments can be conceptualised as a dimension of 'transnational belonging', in which mobile individuals forge and sustain multi-stranded social relations that link together their societies of origin and settlement (see also Basch, Glick Schiller and Szanton Blanc, 1994: 7).

As well as geographically, identity can be ascribed by religion, race or gender or, as was the case for the majority of our civil society organisations interviewees, self-assigned through participation in an administrative body or institution with a distinctive culture or ethos. Identity of oneself explicitly as 'European' was rare, almost never appearing except among those who had travelled and lived outside of Europe, becoming aliens in a strange society. The incorporation of ascribed identities was multilayered, with several, perhaps competing, mutually exclusive or opposed loyalties, expectations and obligations. Multiple sources of identity provide opportunities for agency, the juggling or evaluation of the options of being either engrossed or detached, of being engaged or disengaged, with different identities or collectivities. These opportunities or, depending on point of view, difficulties, can particularly affect migrants, but not exclusively so. Multiple sources of identity can lead to estrangement from each source of identity and marginality to all. Bi-nationally oriented transnational workers can, perhaps without realising it, become migrants that are prey to marginality both with regard to their place of origin and their place of destination.

Experiences of transnational belonging are, of course, not necessarily experiences of belonging to 'Europe' (which in itself can be conceptualised in many different ways). In many stories, 'Europe' was not even mentioned as a source of strong identification, even though the economic and political reality of the EU had clearly influenced the narrators' individual trajectories. The collectivities with which one might bond may be multiple, opening scope for the possibility of juggling competing sources of identification. 
The sources of competing identity can be located at different levels - regional, national or international territorial spheres with distinct cultures and with different administrative bodies or institutions. There can be multilayered incorporations of expectations and obligations with several, perhaps competing, loyalties, impinging upon the same individual, leading to feelings of hybridity or marginality from them all. One can become either engrossed or detached, either engaged or disengaged with any given collectivity.

Interestingly, the feeling of belonging to one's country of origin may become much stronger after the experience of immersion in another culture. When multiple attachments start playing a role, a person may feel internally torn. In this case, interviewees often reflected upon conflicting multiple selves, and in some cases, in order to deal with the problematic situation, hierarchies of belonging are constructed. More positively, multiple sources of identity can provide opportunities for hybridity and the vigour of bringing together unusual or unprecedented cultural mixtures. The children of migrants may in such cases benefit from the movement that made their parents marginal.

\section{Transnational intimate relationships}

This dimension is doubly unique in that it was not recognised as a distinct dimension until we began to collect the first interviews and bring them together for analysis at the project level and, as explained before, due to the significance of personal relationships in many interviews across several of the original sensitised groups, we also chose to make those in transnational intimate relationships into an analysis group in their own right. While being in a transnational relationship or being the product of such a relation- ship can raise many instrumental issues such as residency problems or child custody if a partnership with children breaks down, these could be seen as particular expressions of the 'Structural Conditions' dimension discussed further. The dimension could be seen as a subset of 'Multiple Social Identities and Biographical Identity', except that what makes 'Intimate Relationships' a dimension in its own right is the affective intensity. The primary nature of transnational intimate relationships cannot be compartmentalised and will affect one's identity to the core.

There was a distinct generational component to this dimension in that it can be expressed either from:

1. Being in a relationship oneself with a person from a different culture;

2. Having parents (and hence two different families) who are from different cultures; or

3. Having children with a person from a different culture.

In many interviews of those in nationally mixed relationships, there was a tension within the partnership between being similar and being different. 
Language was an issue of central concern, especially for parents who needed to decide which language(s) their children learned and would speak at home. Another issue is to what extent individuals who move to their partner's country of origin feel accepted by their 'foreign' family-in-law. For those born into a multinational milieu, some individuals felt the need to develop coping strategies to bridge their diverse backgrounds; in those cases 'Europe' could be a useful frame of reference.

\section{Collective action}

Collective action within the context of the Euroidentities project refers to participation in groups, organisations or social movements that have shared goals. Through collective action, such groups may intend to generate social, economic, and/or political transformations, possibly leading to policy changes at local, national, transnational and/or EU levels. The original impetus that created the organisation may come from the existence of a collectivity that shares a common predicament, for example, Catholics suffering discrimina- tion in 1960s Northern Ireland. The psychological processes that persons will undergo as they recognise their common situation and then take steps towards collective action that leads to the formation of an organisation or social movement can have profound biographical effects on their identity.

The biographical effects upon the individual's self experience and selfidentification are key. What makes these types of activities relevant to identity formation is that they necessarily involve taking the perspective of others who are co-jointly involved in the project or movement and dwelling on features shared with them, an explicitly biographical process. Taking the perspective of those relevant others, and being involved in collective activities potentially strengthens notions of shared identity. The perspective taking and passionate involvement in collective activity may thus change one's understanding of self, as a new layer of group identity is added to previous experiences of subjectivity.

This can involve, as in the case of our environmental and reconciliation CSOs, orienting to common arenas of moral discourse that may have a European ambit. Collective action involves experiencing a shared historical trajectory, talking about and constructing an agreed memory of common historical experiences projecting an agreed interpretation of the past onto the past. Its clearest expression in our interviews was in those gleaned from CSO activists, who related their involvement, thinking about and talking with fellow activists about their experience of joint projects with a European component. The concept of collective action has also came up in some of the farmers' stories, when farmers talked about their problems of economic survival and identified their individual difficulties as a more general issue.

The common experience of social networks, organisations or institutional regulations (even unplanned common experience such as being part of a common wave of migration) may lead through action in concert with 
others to shared frames of reference or arenas of moral discourse at the collective level. Since 2000, new flexible diasporic groups have formed, for example, Poles in Ireland and the UK. Their experiences, practices and discourses of multiple belonging were sometimes informed by narratives of Polish 'common history', as Poles from particular regions, or as members of distinct migrant generations (having left Poland in different years, before or after 1990 or 1994). These relations of collective action can include stories of consciousness raising - seeing one's personal biography in terms of history, both externally defined and personally experienced. Externally defined history is the history one is told; either through 'official' historical accounts such as the history one was taught in the formal education system or history related as 'fact' through the media in the form of documentaries or even mainstream daily new media. Further, externally defined history can be the processing or distillation of these events and accounts of events into an 'imagined' history or collective social world of archetypical stories, myths and legends.

History, personally experienced, is concerned with the merging of individual biographical experience with the major events ${ }^{9}$ that society goes through during one's own life span. At times of social change, particularly during times of profound historical change, there can be a merging of historical time with biographical time. Individuals caught up in a collective historical concatenation of events find themselves in a situation that can be perceived as both enabling and disabling. Firstly, there may be a feeling of personally being part of an evolving collective history and con- tributing to it. Secondly, there may be a feeling (and perhaps an experienced reality) of being swamped by historical events that are beyond one's own control where one's personal safety may be jeopardised and in which assets of economic and social capital disappear. This feeling of being caught up in a chaotic or an anomic situation breaks down the security of identity. If the individual can cope, the effect of the trajectory can be positive, leading to a reformulation through processes of 'biographical work' of a revised identity that is more congruent with the changed circumstances and more effective at coping with them. Thirdly, experiencing a common history - a collective trajectory of events leads to collective identity processes as the common experiences are talked and written about $-\mathrm{a}$ 'projection of the recent past' into a shared frame of meaning.

As individuals make sense of the experiential, there is a crossover with the collective social world. Collectively, this latter experiential history can set people apart into one or more age-defined 'cohort generations' - groups socially defined differently from those who are older or younger than them

\footnotetext{
${ }^{9}$ Here, we mean societal events, not the events of one's own life course and working career.
} 
by unique demographic or historical experiences. Many of our interviewees, especially the older ones, could see themselves as part of the collective history of their society and sometimes as contributors to that history. The interviews with civil society organisation activists threw up evidence of three distinct cohort generations: a 'founder' generation of early activists who, working with little or no support from governments or European institutions, set up the organisations and their modes of working; a second generation of adult activists who established modes of working and avenues of access to European institutional funding; and a present-day generation in which many of the activists are recruited or schooled as adolescents into organisations in which there are established organisational cultures and quasi-bureaucratic modes of working. Interestingly, while the timings are different - beginning in the immediate post Second World War period for central European peace and reconciliation groups and beginning during 'the Sixties' for the environmental and Irish-based reconciliation groups - the same features of three generations emerged, albeit decades apart.

At a more practical level, participation in collective action means sharing frames of reference with one's compatriots in an organisation. Acting in concert with others at a collective level of social movements, organisations, common projects or social networks requires developing or drawing up collective rules or institutional regulations for working together and then by and large abiding by them. To put it another way, organisations require bureaucratic regulation. The members of a social movement will be under pressure to conform to 'common causes'. Common 'languages' or words and modes of expression, common styles of working and communicating, common identity markers and shared collective memories and myths will with time develop within an established civil society organisation.

Finally, working together in collective action leads to shared symbolisms and shared frames of reference. As one makes sense of the experienced life, there can be a crossover to the collective social world. The reaction to a common historical experience leads on to the production of a common cultural heritage through mechanisms such as belletristic literature and sharing symbolisms such as using a common language or style of communication, common identity markers or the presence of myths or collective memories held in common.

\section{Cultural production and intercultural translation}

The creation of an artistic programme (broadly defined), as well as generating cultural artefacts themselves can 'feed back' into the person's own sense of self. The original intention of interviewing people that fell within the 'Cultural Contacts' sensitised group was to apprehend these types of behaviour. As well as the creation of belletrist literature, 'high' or 'low'/popular cultural outputs, the production of propaganda, nationalistic or Eurocentric literature or involvement in nationalistic or Eurocentric political activity could have similar effects upon one's identity. 
The development of European identity requires the construction and refinement of communication between the constituent groups within the European Community processes that can be seen broadly as having the effect of cultural design and mediation. Mediation and intercultural liaison work, keystones of the activities that the majority of our interviewees who were involved in peace and reconciliation CSOs carried out, are analogous in that, to be authentic and effective, these require appreciating and taking on the perspective of the other.

Translation is always to some extent interpretation, and genuine translation from one language to another requires a real appreciation and understanding of the culture that is mirrored by the other language. Hence, the processes of language translation and interpretation can be seen as processes that weaken exclusionary divisions through acting as means of mediation and liaison between cultures. Several of our interviewees had either worked or trained as translators.

\section{Inclusion/Exclusion}

It is an irony that, at the same time that barriers between national cultures are eroding within Europe, barriers between Europe and other parts of the world are being strengthened. The Janus face of inclusion/exclusion, by focussing on the positive evaluation of one's own community in contrast to some 'other', has the effect of strengthening identity. The contrast between one's own culture, community or nationality can be either positive or negative and either more or less benevolent.

The focus in the Inclusion/Exclusion dimension was on identity formation in terms of closed space-identity categories, where 'we' communities were defined in opposition to 'them', particularly positively evaluated communities and including the 'imagined communities' of national identity. It was crucial here to create an analytical distinction between physical borders and cultural boundaries. Sometimes borders and boundaries overlap, sometimes they do not. Rather the key is that they are constructed by contrast with the 'other' who has a culture or way of life that is different from one's own.

As many of the autobiographical narratives demonstrated, Europe can be a geographical, cultural and mental space for experiencing 'the new' and 'the other' (both the fascinating and the difficult other). This can be perceived, experienced and narrated as a space for affective possibilities, developing and expanding one's 'self'.

The comparison with 'the cultural other' can be relatively benign; while the 'other' has a culture different to one's own, there are areas of contact and overlap on common core values. In such cases, 'opposites can attract' and there is scope for mutual regard and appreciation. In contrast, the relation to the alien is qualitatively different. The comparison with 'the alien' is more exclusionary; the 'alien' is non-understandable and, rather than 
communication, there can be incomprehension and stereotypes that can bleed over into xenophobic prejudice where there is no understanding due to there being no overlap of core values and moral obligations. There is no communication, only incomprehension. The development of xenophobia can be seen as a process in which the perception of 'the other' is warped into a perception of 'the incomprehensible alien'.

Virtually all of the interviews that fell under the cross-national 'Intimate Relations' were accounts of interactions between mutually appreciating and attracted 'others'. Accounts from interviewees that were the children of such relationships were often about how the relationship between two cultures can play out within a single individual. A significant proportion of the interviews with those in the External to Europe group - both some who had come into Europe from localities that were perceived by individuals within the indigenous population to be religiously, racially or culturally alien and some who had lived outside of Europe in distant lands - dealt with the problems of coping with being perceived as an alien other.

There can be grades of social exclusion. Otherness can arise from the contrast between a centre and a peripheral fringe or between urban versus rural or due to migration from (and to) the fringe. In this way, migration will impact upon the construction of individual and collective identity.

It is also important to identify, where possible, grades of social inclusion/ exclusion in the unfolding biographical narratives. In various interviews with transnational workers and educationally mobile people, for example, narrators directly referred to the dynamics of inclusion/exclusion, describing an increasing or decreasing sense of inclusion in certain fields of local, translocal, national or transnational interaction, or describing processed of fluctuating inclusion/ exclusion. Many narrators identified different relevant social contexts in the course of their life trajectories, in which they experienced changing degrees of belonging. Becoming parents, for example, can give migrants access to social networks of local parents, or being on an Erasmus exchange may integrate a young person temporarily in a group of Erasmus students. We can identify specific local, translocal, national and transnational fields of interaction, and try to understand why and how the interviewees (failed to) gained access and acceptance in these fields.

As well as acting to confirm the exclusivity of the identity of the included, there can be a rise of a sense of 'we-ness' among the excluded. To the extent that these parameters of inclusion and exclusion are being actively constructed rather than being inherited or reproduced, their generation can be considered a biographical process of identity formation.

As well as between different cultures, inclusion/exclusion can operate within the boundaries of a single culture. Social class remains a significant barrier. Two people from similar social strata with similar cultural capital but from different nations within Europe may well have more in common 
than two persons from the same nation who are of different social class. Additionally, while it has not yet been analysed systematically within the project, many interviews had gender divisions as a central concern.

'The centre' versus 'the periphery' can create inclusion and exclusion within a single culture or national entity. The centre/periphery distinction may be phrased in terms of claims to cultural authenticity, morality or creativity (with the centre laying claim to 'High Culture' and being prejudiced against the 'country bumpkin' on the one hand, while on the other the periphery can be valued as the locus of true traditional values). Migration to the centre from the fringe (or movement in the opposite direction) may be an issue.

In cases where there are contested border regions, the centre can present itself as geographically most removed from the contamination of other cultures. At the same time, however, a 'periphery' in turn may contrast itself to a centre that has become contaminated by influences from outside, depicting itself as the genuine location of the wellspring of a culture. Among our farmers who often saw themselves as alienated from national bureaucracies or exploited by middlemen or large-scale food retailers, this centre/periphery contrast can be overlaid with a rural/urban contrast between country and city.

In all these instances, the mutual relationship is one of 'figuration', and need not necessarily be antagonistic - the contrast with 'the other' can be one of the features that determines oneself. To the extent that these parameters of inclusion/ exclusion are being actively constructed rather than being inherited or reproduced, their production can be considered a biographical process of identity formation.

\section{Standardisation and regulation}

'Standardisation and Regulation' refers to procedures, many of which are formal, administrative or organisationally based, for promoting a central or model cultural norm.

The biographical effects of formal education - educational institutions and their practices - can be seen as means of promoting accepted or received 'high' or central cultural values, practices and bodies of knowledge. The promotion of a standard or purified use of language (e.g. hoch Deutsch, the protection of the French language against the incursions of English, standard English language usage and pronunciation, and so on) could be a good example. Reports from 'educationally mobile' interviewees who experienced the Erasmus programme provide both positive and negative examples. The system for exchanging academic credits is intended to allow Erasmus-mobile students to go abroad and maintain momentum towards eventually graduating on time from their home institutions. At the same time, there were often-reported problems with 're-entry' where return- ing Erasmus students found that their educational experiences abroad were 
often undervalued or deemed irrelevant (and in some cases Erasmus students actually were penalised by jealous academic staff in their home institutions). The promotion of the understanding of all forms of 'High Culture' generally could be seen as means for clarifying and reinforcing identity at both the national and the European levels.

The legal system can be seen as a formal mechanism for expressing and enforcing, with sanctions, a society's values. The workings of the legal system and the interpretation of laws and regulations that take place at both the judicial level and at the level of enforcement can be seen as ways in which a society's values are confirmed in practice. Our civil society activists and many of the 'External to Europe' migrants who originated elsewhere made explicit reference to the protection of human rights and the rule of law as European principles. Many farmers across the whole range of countries in which we interviewed, both in the 'old' member states and in the new accession states referred to central European regulations as safeguards against the worst effects of national systems of regulation.

\section{Structural conditions and opportunity structures}

As anticipated, the material effects of changing structural conditions and opportunity structures in Europe as these affected our interviewees' sense of identity were reported across all the sensitised groups. The expressions of these effects were wide-ranging and varied. Structural changes and opportunities feed into the decisions to embark on new trajectories or biographical action schemes. Our narrators' identifications with Europe were affected by the structural realities of EU politics and policies. Changing mar- ket conditions and the relative wealth of different regions of Europe affected the self-perceptions and patterns of mobility of the transnationally mobile workers. The enlargement of the EU has had clear structural implications. The effects of these historical changes were important, particularly changes in security measures and border controls after the entry of the new accession states into the European Union. Due to these legal changes and spurred by economic inequality within the EU, large groups of citizens from the new accession countries have moved to the more affluent countries to find jobs. Supportive funding from the EU was found to be significant, but often in widely contrasting ways. For example, in the case of Erasmus exchanges, funding promotes mobility, whereas the subsidies of the Common Agricultural Policy in effect promote the 'staying put' of farmers.

The effects of technology and scientific advances can alter the relative wealth and opportunity structures of regions. Also, a direct impact of science and technology in recent years has been the transformation in modes of communication through the Internet and related digital technologies that have made a transnational existence both more feasible and more bearable. Similarly, transnational mobility has been transformed by the relative ease of transport and the precipitate drop in the real monetary cost of travelling across Europe. 
Many structural factors can affect the generation of collective identity. The structures of opportunity open to individuals may affect their choice of the collectivities with which they identify. This identification with a group that offers better chances of success in life can be either an unconscious identification with 'the winners' or conscious and strategic (for example, networks of communication, including social networks, open avenues to knowledge of opportunities such as jobs and access to sources of funding).

Opportunity structures can be sited in geography. For example, at a regional level, location in a backward peripheral region with reduced resources and opportunities leads to a different type of regionally based collective identity than location in a centre with privileged access to opportunities, the latest scientific and technological advantages, and other facilities and amenities. Location in a 'centre', whether regionally or organisationally, can confer advantages of access simply through being 'central', being located at the point where knowledge crosses and access to communication and networks is easy. One might also find a 'paralysis of discouragement' for those on the periphery. For example, there can be other structurally determined adverse effects of 'peripherality' upon regions. More developed, prosperous central cores, sometimes abetted by government policies, can drain off the resources of the periphery (such as the exploitation of natural resources or the drain of young, gifted persons to 'the centre').

\section{The public sphere and state-regulated institutions}

This dimension refers to the European political, social, economic and legal institutions associated to a large extent with the European Union and centred mainly in Brussels and Strasbourg - the Europe of political scientists if you will. While we must be careful to remember that Europe is much more than the institutions of the European Union, these institutions and related organisations are crucially significant for people's ideas of Europe and are often what is referred to when people talk about whether they do or do not identify with 'Europe'.

Here, we mean more than just a subset of the opportunity structures discussed previously, but instead some sense of engagement with the causes and obligations of European public spheres. Questions of loyalty, moral bonding or detachment and identification on more than pragmatic grounds come to the fore. The construction of a European identity involves the 'shaping and dimensioning' of the individual's relation to the public sphere and to state-related institutions. If positive, there is a biographical process of bonding morally to the precepts of the public sphere that involves engaging with the duties and obligations of that public sphere. If negative, there is detachment. The most consistent positive sense of engagement came from interviews with the civil society organisations sensitised group where interviewees valued the EU as significant, providing financial support at levels that were not possible either regionally or nationally. However, 'the opposite of love is not hate, 
but indifference' ${ }^{10}$ With the exception of the civil society activists, the vast majority of our interviewees across all our groups were completely detached from engagement with European-level institutions, with no sign of any type of moral bonding to the European public sphere. Farmers in particular also displayed strong levels of frustration with the convoluted systems of bureaucracy and subsidy to which they are subject.

Aside from these decidedly ambivalent attitudes towards the European public sphere of state-regulated institutions, all of the other dimensions for the expression of European identity featured prominently in interviews with one or more of the sensitised groups. This general relevance of Europe across a multiplicity of dimensions and expressed by a wide variety of mechanisms, taken as a whole is convincing evidence for the subtle sphere of a 'European mental space' that is assessed at length in the concluding chapter.

\section{Structure of the book}

Understanding the approaches to biographical interviewing and analysis that were used by Euroidentities is crucial for understanding the project. To that effect, the next chapter, written jointly by the research assistants who worked at the interviewing and analysis 'coalface' across the seven national partner teams, presents the methodological approaches employed, centring on the biographical narrative method that dominated the project. As well as giving a procedural account of what was done, the chapter is genuinely methodological in that it also presents the assumptions and precepts that guided the research.

The original organisation of the project at its outset into substantive work packages each located in a different country, coupled with the creation of two new 'sensitised groups' as additional foci for analysis, meant that the general division of labour across the teams that evolved was one in which in the main each national partner team has focussed upon a different sensitised group. ${ }^{11}$ The result for the organisation of the book is that the

\footnotetext{
${ }^{10}$ From a speech titled 'The Pencils of Indifference' given by Elie Wiesel in Washington, DC on 12 April 1999.

${ }^{11}$ Despite twenty-first century innovations such as Skype conferencing that allow communication between partners in a multinational project and the fact that Euroidentities held regular workshops where the whole project worked together on the analysis of interview transcripts and joint discussion of findings, geography still makes a difference and it has proved more practical so far for most of the project's writing to be done within national teams. However, while aside from the methodological chapter all the chapters have been written solely by members of the same national teams, it would be wrong to underestimate the amount of analytic cross-fertilisation that has gone on. There has been considerable interpenetration of ideas and perspectives over the span of the project and it would not be an overstatement to say that all the named authors in the book can be considered to some degree to be authors of all the chapters.
} 
methodological chapter is followed by seven chapter blocks that follow the seven 'sensitised groups' that have formed the substantive foci of the Euroidentities project. The original plan had been to have each analysis team write two chapters - a 'conceptual' chapter that would present the main findings arising from the sensitised group in question, followed by a linked 'case study' chapter that would illustrate the conceptual findings through a detailed presentation of one or more cases. ${ }^{12}$ In the end, while most teams maintained this format, several chose, mainly for practical reasons, ${ }^{13}$ to produce a single chapter with excerpts from a number of inter- views. It is worth pointing out that the book can be read in two ways: as a book about European identity but also as a textbook about the application of biographical methods, particularly the biographical narrative method, to an empirical question. While very few people would consider themselves to be 'Europeans' over their national, regional, local or other nongeographic identities, the project did find convincing evidence of an evolving 'European Mental Space'. The final chapter by Schütze and Schröder-Wildhagen, 'European Mental Space and its Biographical Relevance', grapples with the presentation of a key finding of the project, the psychological fields of reference or orientation that many, perhaps the majority, of people living in the continent today have to 'Europe' or European institutions that transcend regional and national boundaries while still being distinct from globalisation and delimited by the geographical and institutional horizons of the continent.

\footnotetext{
${ }^{12}$ Harking back to the founding days of biographical research, the latter 'case study' chapters can be seen as a homage to Władek Wiszniewski, the (in)famous life story to which Thomas and Znaniecki applied annotated footnotes to exemplify the experiences of The Polish Peasant in Europe and America.

${ }^{13}$ For example, several teams found it difficult to locate one or two cases that in themselves could illustrate the range of their findings adequately.
} 